\title{
Tire Industry Products as an Alternative Fuel
}

\author{
Beata Ślusarczyk*, Magdalena Baryń, Sebastian Kot \\ Faculty of Management, Czestochowa University of Technology, \\ Armii Krajowej 19 B, 42-200 Częstochowa, Poland
}

Received: 7 January 2016

Accepted: 22 January 2016

\begin{abstract}
One of the main requirements for products of the tire industry is durability. This feature is desirable in the operation phase, but causes problems during recycling. The tire degradation process takes tens of years, and their storage is associated with a risk of fire and the release of many hazardous substances to the atmosphere. It is therefore necessary to find methods for safe and environmentally sound management of this waste. One method for disposing of worn tires is to use them as alternative fuel. The purpose of this article is to identify ways of managing rubber waste in the countries of the European Union and defining the role and place of energy recovery in the economy of worn tire industry products.
\end{abstract}

Keywords: used tires, end-of-life tires, alternative fuel

\section{Introduction}

The constant development of the automotive industry is inextricably linked to the emergence of larger amounts of tires, which after a period of use become waste. In 2013 in the European Union alone more than 263 million tires - representing approximately $20 \%$ of annual global sales - were sold, with tire production amounting to almost 4.7 million tons. And in turn in 2012 there were almost 2.5 million tons of used tires acquired that were no longer suitable for use in accordance to the intended application (these figures do not include partially used tires, which can be reused) $[1,2]$. This raises the problem of development of such a large amount of tires, which must take into account the fact that they are among the most troublesome waste [3]. Their accumulation in landfills is dangerous, as in the case of a fire a lot of harmful substances are released into the air, which causes contamination of not only the air but also water

*e-mail: jagoda@zim.pcz.pl and soil. Such a fire is also very difficult to extinguish. According to Meddah et al., used tires can also constitute a favourable environment for all kinds of rodents, insects, and mosquitoes [4]. In such a situation it is necessary to find a way to reclaim and dispose of waste tires. One idea for using tires unsuitable for further use is as an alternative fuel. This method of managing used tires also fits perfectly within EU and global demands to replace conventional fuels with alternative fuels or renewable energy sources wherever possible [5]. Tires as fuel are most commonly used in cement factories and paper industry companies, and more recently in power plants and heating plants $[6,7]$.

\section{European Union Legislation in the Field of Waste Tires}

Environmental and recycling of materials issues have been one of the orbits of the European Union's interest for a long time. Although in the founding treaties of the European Communities did not yet mention it [8], the 


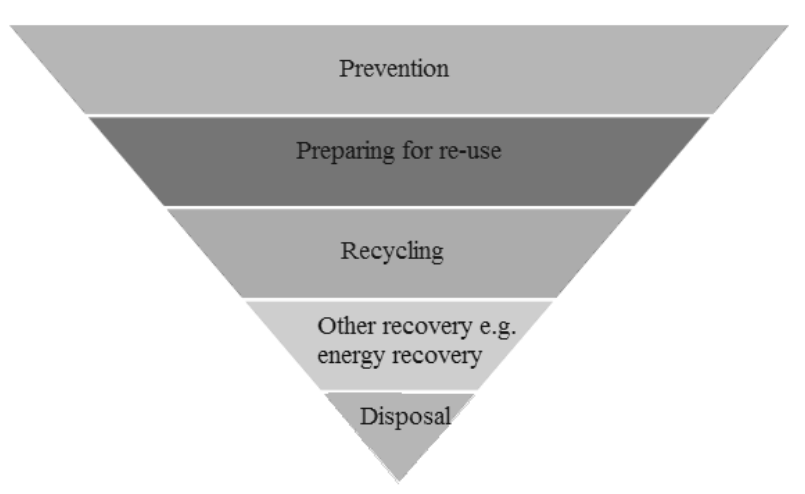

Fig. 1. The hierarchy of waste procedures.

first regulation at the European Community level affecting waste management dates back to 1975 . But by far the greatest importance for the management of waste, including worn tires, is the directive of the European Parliament and Council 2008/98 / EC of 19 November 2008 on waste and repealing certain directives. This act established the hierarchy of waste procedures (Fig. 1) and introduced the concept of extended producer responsibility for waste [9]. This directive, like several other EU documents, recommended the use of procedures of life cycle assessment (LCA) [10]. LCA allows for determining the effects of the product on the environment in all phases of its life: from raw materials to production, through the process of production, distribution, and consumption to disposal [11].

The implementation of the Directives and other EU laws is the responsibility of each member state. In some matters, however, EU members were left some freedom in the process of achieving their goals. One such area is the organization of the waste management system. In terms of waste tires the member states are currently using one of three models (Fig. 2), while while the most popular is definitely the first [12]:

- Extended producer responsibility: management of worn tires is the responsibility of the manufacturer or importer of tires; these entities are responsible for organizing the collection of waste tires, but in practice often convey the task to specialist recycling organizations.

- Tax system: producers or sellers pay to the state specific charges associated with the production of tires (count them in tire production costs); management of worn tires is conducted by an organization of recovery funded by the state paid by the producers and sellers of tires.

- The free market: in this system it is assumed that used tires can be a valuable secondary raw material.

The system of taxes is currently used only in Denmark and Slovakia, while the Slovak Republic is currently in the process of changing the system to the producer responsi-

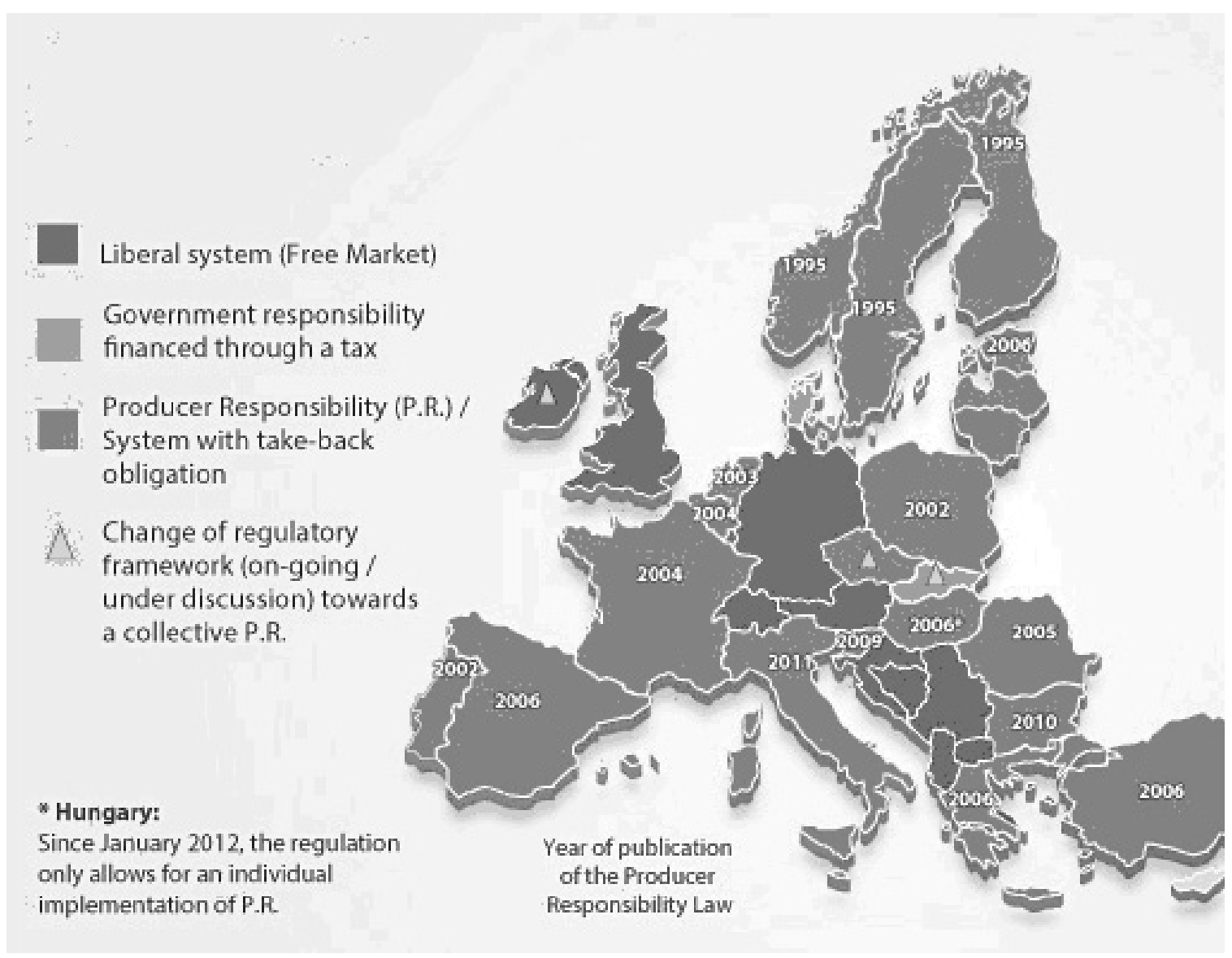

Fig. 2. Models of end-of-life tire waste management across Europe [13]. 
bility model. The producer responsibility system was first applied by Scandinavian countries that introduced it in 1995.

\section{Ways to Use Tires}

Worn tires can be divided into two basic groups: partly worn tires, which are suitable for reuse as intended (partworn tires), and tires completely worn out, whose life cycle has come to an end (end-of-life tires, or ELT). The wear rate of the tire determines the available methods for their use or disposal.

Partially worn tires can be used in two ways. If their technical conditions permit it, they can be reused without undergoing any technological processes. If they do not meet the technical standards for admission to traffic while they are not yet completely worn out, they can be subjected to a process of retreading. It is a process widely used, economically cost-effective, and - just as important - safe for the environment. In addition, partly worn tires (as well as ELT tires) can be internationally traded.

Completely worn tires are managed in three ways. They can be subjected to material recycling or pyrolysis, or they may finally be disposed of with energy recovery. Among these methods, material recovery includes by far the widest range of applications. Worn tires may have different applications depending on the fineness. Whole tires are used, for instance, for the construction of artificial reefs in the sea and oceans as a hedge against waves and protecting riverbanks from erosion [14]. Much wider use, however, can be found for shredded tires, which may take the form of fragments $(50-300 \mathrm{~mm})$, chips (10-50 mm), granules (1-10 mm), and rubber powder (less than $0.5 \mathrm{~mm}$ ). Shreds and chips are used to build tunnels and bridges, embankments, ground paving, racecourses, and drainage applications, and they provide lightweight fill and can also be used as insulating layers $[15,16]$. Granules and rubber powder are in turn used in the construction of sports field surfaces, running tracks, playgrounds, noise barriers, railway crossings, or sleepers cushioning impact, and in the production of paving, roofing and insulation materials, road markings, sports equipment, footwear, carpets and windshield wipers, floor mats for animals, and flooring.

There is an opportunity cost for using used tires as an energy source, as they can be incorporated into asphalt to make it more flexible, safer to drive, and longer lasting. Worn tires can be used in the construction and repair of roads. Shu and Huang describe using tires to create asphalt [17]. On the other hand, Lin, Huang, and Shern have investigated and proven the usefulness of powdered tires for absorbing oil in disasters at sea [18].

Another way to manage waste tires is pyrolysis. In this process the tires are heated at a high temperature in oxygen deficiency, which causes the production of solid, liquid, and gas products. Pyrolysis is a process much more complicated than usual tire shredding, but the resulting products are easy to store and transport [19]. The subject of pyrolysis of waste tires is fairly well characterized in the literature. Vihar, Seljak, Oprešnik, and Katranie [20], plus Martinez, Ramos, Armas, Murillo, and Garcia [21] examined the possibility of applying the oil, being a result of pyrolysis of worn tires in the engines. The theme of pyrolysis of waste tires was also dealt with, among others, by Undri, Rosi, Frediani, and Frediani, [22] plus Banar, Akyildiz, Ozkan, Cokaygil, and Onay [23].

The last way to manage waste tires is their incineration with energy recovery. The tires may be co-fired with coal or other fuels. These processes are carried out mainly in cement factories in the production of clinker. Tires and other rubber waste are an attractive alternative to coal due to the fact that they have a high calorific value - higher than many other fuel materials (see Table 1). This method of using waste tires allows us on the one hand to avoid their storage (which is illegal) and on the other to contribute to reducing the use of non-renewable energy sources (mainly coal).

Table 1. Comparison of the calorific value of waste tires with other combustible materials [24].

\begin{tabular}{|c|c|}
\hline Combustible material & Caloric values MJ/kg \\
\hline Biomass (mix) & 15.1 \\
\hline Paper / cardboard & 17.4 \\
\hline Fabrics & 18.4 \\
\hline Coal & 26.4 \\
\hline Worn tires & 31.4 \\
\hline Petroleum & 39.5 \\
\hline
\end{tabular}

An extremely important feature of the use of worn tires as an alternative fuel in cement plants is their complete combustion without the formation of ash and other residues. The risk of hazardous emissions into the atmosphere is also eliminated, as metals released from the tires during combustion in a cement kiln are stably bound with clinker, while improving its properties. Pipilikaki, Katsioti, Papageorgiou, Fragoulis, and Chaniotakis show that burning waste tires in cement kilns is a favourable solution from an ecological point of view, but at the same time attention has to be paid so that, while using too many tires, the zinc content in cement is not exceeded [25]. This method of disposal of worn tires is therefore ecologically justified, especially if we take into account the benefits of conventional fuels saved by the use of tires. It should be remembered that the combustion of tires is safe for the environment only purpose-built installations and at the proper temperature. Therefore, they cannot be burned in a home stove (which unfortunately in Poland is still a fairly common practice) as too low a combustion temperature causes the release of many harmful substances into the atmosphere. 


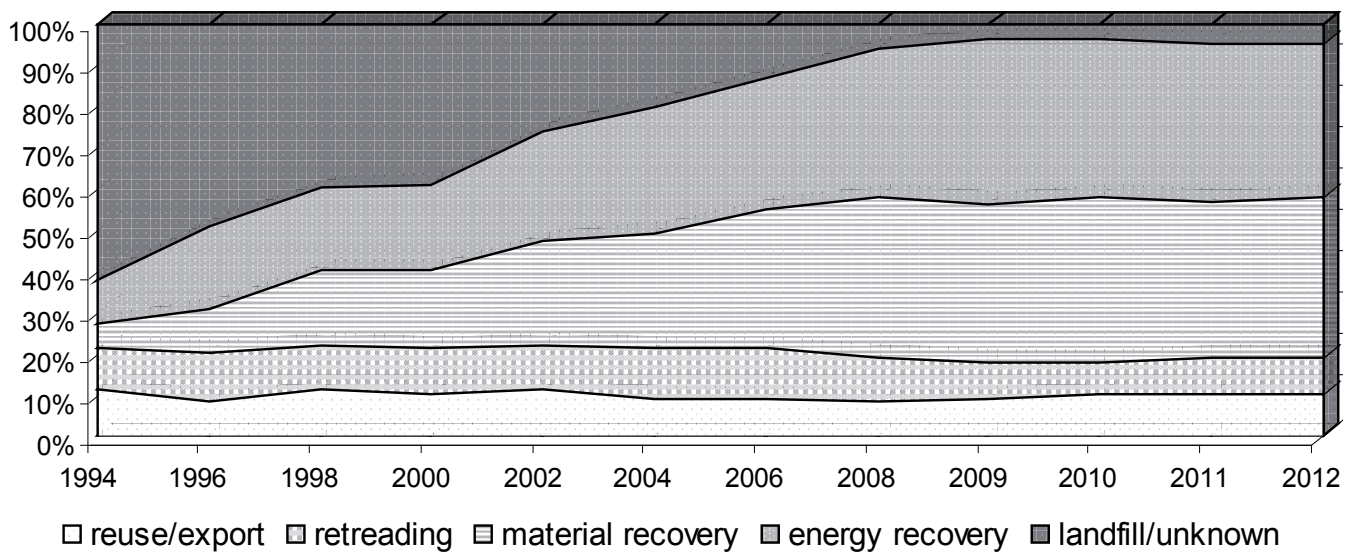

Fig. 3. Share of particular methods in the overall structure of the management of worn tires in European Union countries in 1994-2012. Source: own study based on ETRMA data.

\section{The Importance of Energy Recovery in Terms of Managing Worn Tires in the European Union}

As has already been stated, the European Union attaches great importance to the management of worn tires and prohibits their admission to landfills. At the same time, it promotes various forms of material recycling and incineration of tires with energy recovery. Fig. 3 presents the changes in the share of particular methods of management of worn tires in the overall structure of this management in the European Union countries in 1994-2012.

In 1994 the vast majority of used tires used to go to landfills, but due to restrictive EU regulations, landfills now hold approximately $5 \%$ of worn tires. This is not yet a satisfactory result because ultimately the management of worn tires needs to reach $100 \%$ so that no worn tires get to landfills or other unknown locations.

The most common methods of waste rubber management are now energy recovery and material recycling, which increases their importance at the expense of land- fills. These two categories recorded the greatest progress, which is certainly associated with a strong and effective promotion of the use of these methods. Reuse, retreading, or export have had over the years stable share in the management of waste tires and reach in total a value of around $20 \%$. Bearing in mind that re-use/export and tire retreading apply to partially used tires, it can be concluded that this type of tire accounts for about $20 \%$ of tire waste, while the rest are completely worn tires.

In 1994-2012 the rate of recovery of ELT tires significantly increased. This is testified to by the increasing share of recycled materials and energy in the overall structure of the management of worn tires, achieved at the expense of storage (or unknown applications or locations). More detailed data on the quantities of ELT tires produced in a year and the number of ELT tires subjected to material and energy recycling are presented in Fig. 4.

Every year European Union countries together with Switzerland and Norway generate more than 2.5 million tons of completely worn tires. This amount in 2004-12 is at a fairly stable level and is subject to slight fluctuations.

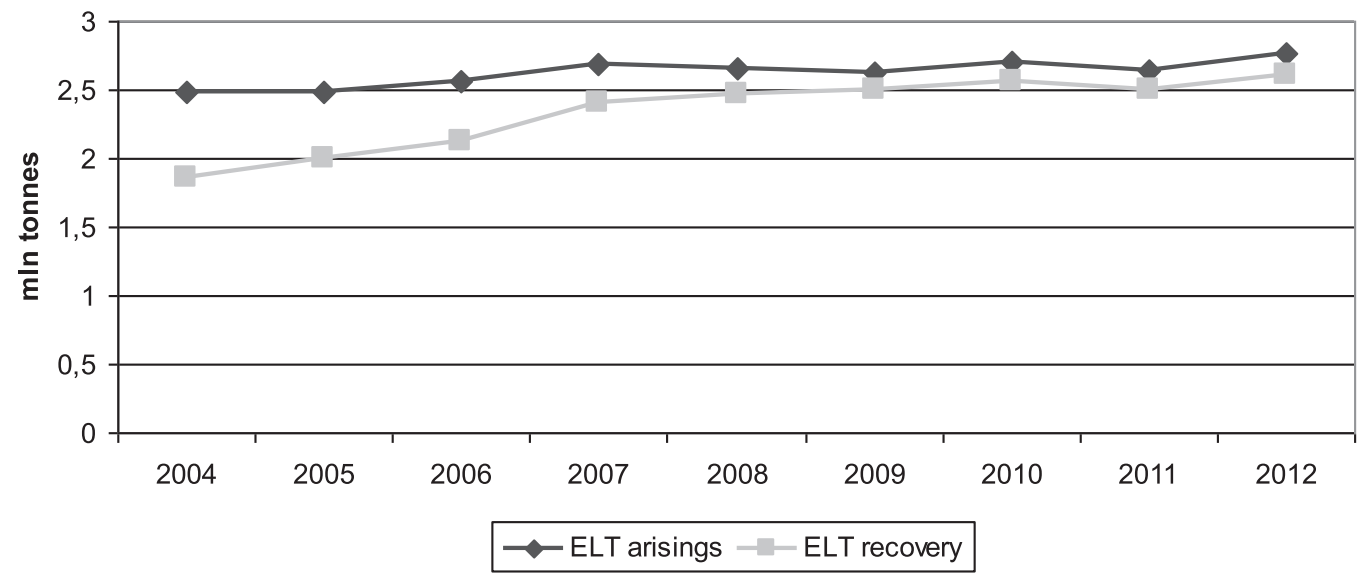

Fig. 4. Comparison of the amount of ELT tires managed within the framework of material and energy recovery with the number of ELT tires produced 2004-12 in the EU (including Switzerland and Norway).

Source: own study based on ETRMA data. 
Table 2. Material and energy recovery of completely worn tires in 2009-212 in the EU (million tons).

\begin{tabular}{|l|c|c|c|c|}
\hline \multirow{2}{*}{\multicolumn{1}{c|}{ Type of recovery }} & \multicolumn{3}{c|}{ Year } \\
\cline { 2 - 5 } & 2009 & 2010 & 2011 & 2012 \\
\hline Material recovery, including: & 1,20 & 1,31 & 1,26 & 1,34 \\
- land and water engineering & $20 \%$ & $18 \%$ & $13 \%$ & $12 \%$ \\
- product application & $80 \%$ & $82 \%$ & $87 \%$ & $88 \%$ \\
\hline Energy recovery, including: & 1,29 & 1,25 & 1,23 & 1,26 \\
- cement plants & $97 \%$ & $92 \%$ & $93 \%$ & $91 \%$ \\
- other (electricity plants, communal heating plants) & $3 \%$ & $8 \%$ & $7 \%$ & $9 \%$ \\
\hline
\end{tabular}

Source: own study based on ETRMA data.

In turn, the number of tires managed in recovery is steadily growing (except for 2011). A positive phenomenon is the significant increase in the use of ELT tires. This ratio increased from approx. $75 \%$ in 2004 to $94 \%$ in 2012 . It should be emphasized that since 2010 we have observed a slight decrease in the use of completely worn tires within energy and material recovery, which may give some grounds for concern.

When analysing the level of recovery of ELT tires it is also important to consider the recovery of material and the method of energy recovery. Data related to this aspect are included in Table 2.

Both types of recovery are at a similar level, which makes the structure of the management of waste tires quite balanced. It is not possible, therefore, to unequivocally indicate which method of disposal is more important and plays a larger role in tire waste management. But a slight increase in the importance of material recovery, to which from 2010 a minimum greater part of worn tires is subjected, should be noted. However, this is such insignificant growth that it is difficult to predict future trends on its basis.

In the case of material recovery, far more important is the use of ELT to product applications (product recycling), and over the analysed period its meaning is still growing. As far as energy recovery is considered, this method is mainly used in cement plants, but slowly more and more energy from worn tires is recovered in other places, like power plants or city heating plants. A growing number of places where energy recovery is run may result in an increased demand for worn tires, which, given the increased share of material recovery, may lead in some cases to a shortage of this type of waste.

Knowing the situation concerning the management of waste tires in the European Union as a whole, we may be tempted to also examine the issue at the level of individual member states. Data on selected countries are included in Table 3.

Most used tires are generated by Germany, slightly fewer by France and the United Kingdom, and the least by the Czech Republic and Sweden. These discrepancies arise easily from the population and level of development of the automotive industry in these countries. In the Czech Republic, Sweden, and the UK we can observe a decrease in the number of waste tires while in France, Germany, and Poland, this amount is increasing.
The Czech Republic is the only country that uses partly worn tires only through retreading. France, Germany, and the UK, which are countries that produce the most worn tires, can boast the best results of partially used tire management. In terms of exports, the definite leaders are currently the Germans, who export more than three times as many partially used tires than the United Kingdom, which is the second in this ranking. France exported tires only in 2004-06 (this practice was later discontinued). Sweden is in turn the only country that does not currently apply tire retreading.

In all countries, a substantial amount of tires are ELT, which are completely worn-out tires. Individual countries manage waste in different ways, wherein over the years the approach to the various methods has evolved. The Czech Republic is the only country where in 2004 there was no tire recovery of ELTs, while this does not necessarily mean that all worn tires were transferred to landfills. The fate of some of them is unknown; therefore we cannot say what happened to them and how they were disposed of (or if in general, they were disposed of). Also, only in the Czech Republic in 2006 was material recovery of waste tires not applied. In other countries waste management of tires is definitely at a higher level, while in Germany, Poland, and Sweden energy recovery is used on a larger scale, while in the UK a greater emphasis is placed on material recovery. The largest disparity in the application of both methods is evident in Poland, where even 3-4 times more tires were used for energy recovery than for material recovery. This disproportion, however, has been significantly reduced in recent times. Among the analysed countries France stands out, in which case one cannot clearly determine which recovery method is preferred.

Some trends on the use of tires for the recovery of materials and energy can be seen when analyzing the data contained in the table. In the Czech Republic the number of tires used in both methods is increasing. In Germany, the amount of recycled tire material is increasing, while their number in the recovery of energy is decreasing. In Poland, initially there was an increase in the use of tires in both methods, but since 2010 the volume of tires for energy recovery has been declining. In other countries the number of tires used for material recovery is declining, while the number of tires used for energy recovery is increasing. Some striving to achieve a state of relative equilibrium can be seen at the same time, where both methods 
Table 3. Economy of worn tires in selected countries of the European Union (values are given in thousands of tons).

\begin{tabular}{|c|c|c|c|c|c|c|c|c|}
\hline \multirow{2}{*}{ Year } & \multirow{2}{*}{$\begin{array}{l}\text { Used tyres } \\
\text { arising }\end{array}$} & \multicolumn{3}{|c|}{ Part-worn tyres } & \multirow{2}{*}{$\begin{array}{l}\text { ELT material } \\
\text { recovery }\end{array}$} & \multirow{2}{*}{$\begin{array}{l}\text { ELT energy } \\
\text { recovery }\end{array}$} & \multirow{2}{*}{$\begin{array}{l}\mathrm{L} \text { andfilly } \\
\text { unknown n }\end{array}$} & \multirow{2}{*}{$\begin{array}{c}\text { UT treated } \\
(\%)\end{array}$} \\
\hline & & Reuse & Export & Retreading & & & & \\
\hline \multicolumn{9}{|c|}{ Czech Republic } \\
\hline 2004 & 80 & - & - & 12 & - & - & 68 & $15 \%$ \\
\hline 2006 & 61 & - & - & 12 & - & 19 & 30 & $51 \%$ \\
\hline 2009 & 48 & - & - & 2 & 8 & 24 & 14 & $71 \%$ \\
\hline 2010 & 57 & - & - & 2 & 9 & 29 & 17 & $70 \%$ \\
\hline 2012 & 56 & - & - & 2 & 15 & 27 & 12 & $79 \%$ \\
\hline \multicolumn{9}{|c|}{ France } \\
\hline 2004 & 398 & 20 & 20 & 55 & 157 & 106 & 40 & $90 \%$ \\
\hline 2006 & 372 & 13 & 13 & 50 & 189 & 107 & - & $100 \%$ \\
\hline 2009 & 364 & 32 & - & 23 & 128 & 180 & 1 & $100 \%$ \\
\hline 2010 & 381 & 36 & - & 43 & 166 & 147 & - & $100 \%$ \\
\hline 2012 & 416 & 45 & - & 48 & 148 & 175 & - & $100 \%$ \\
\hline \multicolumn{9}{|c|}{ Germany } \\
\hline 2004 & 585 & 15 & 38 & 60 & 124 & 310 & 38 & $94 \%$ \\
\hline 2006 & 585 & 15 & 51 & 59 & 139 & 321 & - & $100 \%$ \\
\hline 2009 & 571 & 10 & 69 & 49 & 177 & 266 & - & $100 \%$ \\
\hline 2010 & 614 & 10 & 84 & 45 & 215 & 260 & - & $100 \%$ \\
\hline 2012 & 605 & 10 & 93 & 78 & 190 & 234 & - & $100 \%$ \\
\hline \multicolumn{9}{|c|}{ Poland } \\
\hline 2004 & 146 & 1 & 1 & 21 & 10 & 56 & 57 & $61 \%$ \\
\hline 2006 & 160 & - & - & 22 & 24 & 88 & 26 & $84 \%$ \\
\hline 2009 & 259 & - & - & 16 & 53 & 190 & - & $100 \%$ \\
\hline 2010 & 239 & - & - & 20 & 51 & 168 & - & $100 \%$ \\
\hline 2012 & 214 & 12 & - & 17 & 85 & 100 & - & $100 \%$ \\
\hline \multicolumn{9}{|c|}{ Sir eden } \\
\hline 2004 & 90 & 1 & 7 & 16 & 32 & 34 & - & $100 \%$ \\
\hline 2006 & 88 & - & 4 & 16 & 34 & 34 & - & $100 \%$ \\
\hline 2009 & 70 & - & 2 & - & 27 & 41 & - & $100 \%$ \\
\hline 2010 & 79 & - & 1 & - & 31 & 47 & - & $100 \%$ \\
\hline 2012 & 77 & - & 1 & - & 28 & 48 & - & $100 \%$ \\
\hline \multicolumn{9}{|c|}{ United Kingdom } \\
\hline 2004 & 475 & 32 & 34 & 55 & 212 & 72 & 70 & $85 \%$ \\
\hline 2006 & 486 & 33 & 35 & 57 & 254 & 74 & 33 & $93 \%$ \\
\hline 2009 & 479 & 91 & 16 & 41 & 216 & 115 & - & $100 \%$ \\
\hline 2010 & 465 & 44 & 54 & 32 & 224 & 102 & 9 & $98 \%$ \\
\hline 2012 & 363 & 26 & 27 & 28 & 143 & 127 & 12 & $97 \%$ \\
\hline
\end{tabular}

Source: own study based on ETRMA data.

to manage tires are similar in volume. It is best seen on the example of the UK, where in 2004, three times more tires were used for the recovery of material than for energy recovery, and in 2012 the number of tires managed using these two methods was similar.

In terms of recovery rate, the leader is Sweden, which is the only one of the analysed countries that already in 2004 had reached a rate of recovery of $100 \%$. The worst situation is in the Czech Republic, where in 2012 the recovery rate was just under $80 \%$, although it must be noted that this is an increase by 65 percentage points compared to 2004. Besides the Czech Republic, only the UK does not currently achieve a maximum degree of management of waste tires. Bearing in mind the ban on accepting worn tires in landfills, introduced in 2006, it can be inferred that the fate of part of the tires in these two countries is unknown. In other countries since 2006 (in Poland since 2009), the recovery rate stands at $100 \%$.

Poland is a country in which energy recovery is of utmost importance, therefore it is worth having a closer look the share of tires in the structure of alternative fuels. In view of the fact that the vast majority of energy recovery of waste tires occurs in cement kilns, the data from these plants can be considered representative. The share of tires and rubber waste in the structure of alternative fuels in cement plants in Poland in 2008-12 is shown in Fig. 5.

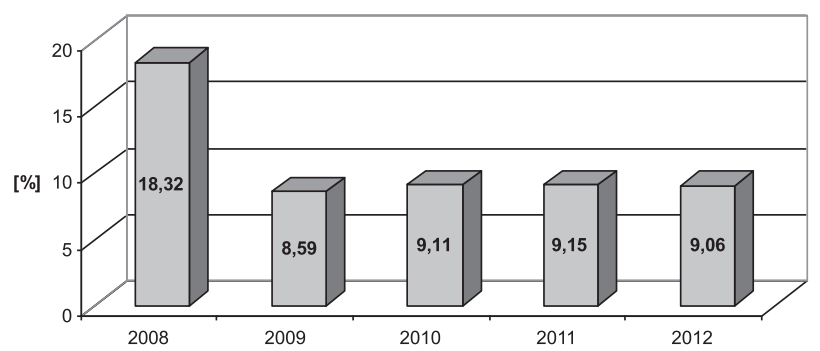

Fig. 5. The share of used tires and rubber waste in the structure of alternative fuels in cement plants in Poland (in \%).

Source: own study based on data from the Association of Cement Producers. 
In 2009 there was a significant decrease in the share of tires and rubber waste in the structure of alternative fuels in cement plants in Poland. Since then it has been kept stable at around 9\%, and this result can be considered quite good. The use of tires as an alternative fuel in cement plants is limited by several respects. The most important of these is the need to maintain appropriate parameters of cement, which could be disrupted by too large a share of tires in the feed energy to the cement kiln. The second issue is the limited availability of tires on the market. The recovery rate of waste tires in Poland is $100 \%$, so there are no free resources that could be managed in cement plants for energy recovery. This can cause cement factories to have trouble obtaining necessary quantities of waste tires.

\section{Conclusions}

Tires, although they are designed for durability, have a limited life cycle. This cycle can be extended by retreading, but one cannot do this indefinitely. All tires included in the category ELT constitute waste that must somehow be managed. Development of this may take the form of material recovery or energy recovery. Recovery of material covers both whole tires (used, for example, for the construction of artificial reefs and protection embankments) and shredded tires, taking the form of shreds, chips, granules, and fine grains. Energy recovery is conducted mainly by the cement industry, which burns more than $90 \%$ of recycled tires using this method. It has been prohibited in the European Union (since 2006) to accept tires at landfills. This means that member states should achieve 100\% recovery levels. However, not all countries are successful at this. The Czech Republic in 2012, for example, reached this indicator at a level of only $80 \%$. At the other extreme are countries like Sweden and France, for example, where for many years worn-out tires have been fully managed.

Individual EU member states may pursue their own waste management policies, with emphasis on the use of the method chosen, provided that this is of course in line with the recommendations of the Community. A manifestation of such independence is the right to create a management system of worn tires and a choice between a system of extended producer responsibility, a system of taxation, and the free market. A good example of tire producer responsibility is inserting hi-tech sensors in tires to assess the quality of road surface and advise of dangers ahead. For an additional small step, tires could be equipped with wear sensors to tell when they will be discarded and give an estimate of tires coming to energy generator plants. Individual countries are distinguished from one another not only by the type of system or the size of the waste generated by the system of tire waste, but also by the management method. This is why in the UK the basic form of management of completely worn out tires is the recovery of material, while in Poland the majority of waste tires are intended to be processed for the recovery of energy in cement plants. The use of tires as an alternative fuel in cement kilns is a favourable solution from both environmental and economic points of view. This allows for safe disposal of waste tires and contributes to saving conventional fuels while improving the properties of manufactured cement. Worn tires are therefore raw material desired by the cement plants, which at least in Poland has in recent years become a growing problem with satisfying the reported demand. The increasing use of material recovery of waste tires makes the secondary market run out of raw material. The recovery rate of used tires has reached the maximum value, so the only way to increase the available quantity of rubber waste would have to be imports from abroad. This, however, is definitely less viable economically, and in addition it is associated with a whole range of ecological requirements related to importing waste into the country. Cement plants must therefore develop a way to gain the greater part of the pool of used tires in the country, or find other alternative fuels that meet the requirements of co-combustion in cement kilns.

\section{References}

1. ETRMA. European Tire \& Rubber Industry. Statistics Edition 2013. 2013.

2. ETRMA. European Tire \& Rubber Industry. Statistics Edition 2014. 2014.

3. BUDICA I., BUSU O.V., DUMITRU A., PURCARU M.L. Waste management as commitment and duty of citizens. Polish Journal of Management Studies. 11 (1), 7, 2015.

4. MEDDAH A., BEDNAR M., BALI A. Use of shredded rubber tire aggregates for roller compacted concrete pavement. Journal of Cleaner Production, 72, 187, 2014.

5. STEFANELLI N.O., JABBOUR C.J.C., DE SOUSA JABBOUR A.B.L. Green supply chain management and environmental performance of firms in the bioenergy sector in Brazil: An exploratory survey. Energy Policy, 75, 312, 2014.

6. BRZEZIŃSKI S., GRABARA J., KOT S. Outsourcing performance in the power plants. Elektroenergetika 2015, The 8th International Scientific Symposium on Electrical Power Engineering, 2015.

7. BRZEZIŃSKI S., GRABARA J., PIETRASIEŃSKI P. Concept of Sustainable Development as an Opportunity for Energy Sector in Poland. Metalurgia International 18 (11), 36, 2013.

8. MATUSZAK-FLEJSZMAN A., HADRYJAŃSKA B., GÓRNA J. Changes in Environmental Management after Poland's Entry to the EU - the Example of Dairy Sector. Polish Journal of Environmental Studies. 22 (3), 782, 2013.

9. Directive 2008/98/EC of the European Parliament and of the Council of 19 November 2008 on waste and repealing certain Directives, 2008.

10. KULCZYCYKA J., LELEK Ł., LEWANDOWSKA A., ZAREBSKA J. Life Cycle Assessment of Municipal Solid Waste Management - Comparison of Results Using Different LCA Models. Polish Journal of Environmental Studies. 24 (1), 126, 2015.

11. DZIKUĆ M., PIWOWAR A., Life Cycle Assessment as an Eco-Management Tool within the Power Industry. Polish Journal of Environmental Studies. 24 (6), 2382, 2015.

12. RAMARAD S., KHALID M., RATNAM C.T., LUQMAN CHUAH A., RASAMI W. Waste tire rubber in polymer blends: A review on the evolution, properties and future. Progress in Materials Science. 72, 103, 2015. 
13. http://www.etrma.org/tires/ELTs/ELT-management/ELTmanagement-schemes [online] (accessed. 02.12.2015).

14. GRONOWICZ J., KUBIAK T. Used tires recycling. Problemy Eksploatacji. 2, 9-16, 2007 [In Polish].

15. THE EUROPEAN TIRE RECYCLING ASSOCIATION. Introduction to Tire Recycling: 2013. Twenty years in tire recycling in the EU. no date.

16. TRZASKA E. Development of waste tires in road construction. Nafta-Gaz. 10, 949, 2010 [In Polish]

17. SHU X., HUANG B. Recycling of waste tire rubber in asphalt and portland cement concrete: An overview. Construction and Building Materials 67, 217, 2014.

18. LIN Ch., HUANG Ch.-L., SHERN Ch.-Ch. Recycling waste tire powder for the recovery of oil spills. Resources, Conservation and Recycling. 52, 1162, 2008.

19. AYDIN H., ILKIKIC C. Optimization of fuel production from waste vehicle tires by pyrolysis and resembling to diesel fuel by various desulfurization methods. Fuel. 102, 605, 2012.

20. VIHAR R., SELJAK T., OPRESNIK S.R., KATRASNIK T. Combustion characteristics of tire pyrolysis oil in turbo charged compression ignition engine. Fuel. 150, 226, 2015.

21. MARTINEZ J. D., RAMOS A., ARMAS O.,MURILLO R., GARCIA T. Potential for using a tire pyrolysis liquid-diesel fuel blend in a light duty engine under transient operation. Applied Energy. 130, 437, 2014.

22. UNDRI A., ROSI L., FREDIANI M., FREDIANI P. Upgraded fuel from microwave assisted pyrolysis of waste tire. Fuel. 115, 600, 2014.

23. BANAR M., AKYILDIZ V., OZKAN A., COKAYGIL Z., ONAY O. Characterization of pyrolytic oil obtained from pyrolysis of TDF (Tire Derived Fuel). Energy Conversion and Management. 62, 22, 2012.

24. WASILEWSKI R., STELMACH S. Energy recovery in combustion and co-combustion of waste tires industrial processes. Archiwum Gospodarki Odpadami i Ochrony Środowiska. 11 (2), 64, 2009 [In Polish].

25. PIPILIKAKI P., KATSIOTI M., PAPAGEORGIOU D., FRAGOULIS D., CHANIOTAKIS E. Use of tire derived fuel in clinker burning. Cement \& Concrete Composites. 27, 843, 2005. 